\title{
Control de calidad del material biológico humano recolectado con fines de investigación
}

\section{Quality control of human biological material for use in research}

\author{
Elizabeth Guío-Mahecha1', María C. Páez-Leal², María L. Luna-González², Silvia Becerra-Bayona², \\ Laura E. Corzo-Prada², Norma Serrano-Díaz ${ }^{1,2}$
}

\begin{abstract}
Forma de citar: Guío-Mahecha E, Páez-Leal MC, Luna-González ML, Becerra-Bayona S, Corzo-Prada LE, Serrano-Díaz N. Control de calidad del material biológico humano recolectado con fines de investigación. Rev Univ Ind Santander Salud. 2016; 48(3): 393-409. DOI: http://dx.doi.org/10.18273/revsal.v48n3-2016013 @(c) () Є
\end{abstract}

\section{RESUMEN}

El material biológico humano proporciona información valiosa sobre niveles de metabolitos asociados con el desarrollo de cierto tipo de enfermedades, por tanto es una herramienta importante para monitorear respuestas a tratamientos e incluso identificar nuevos mecanismos de intervención. Los procedimientos a los que se expone el material biológico desde su obtención hasta su fase analítica, son denominados variables pre-analíticas, las cuales, pueden tener un efecto directo en la detección de metabolitos y por consiguiente sobre resultados de proyectos de investigación, en particular en ausencia de procesos estandarizados que garanticen el control de calidad del material biológico. La presente nota técnica tiene como finalidad resaltar algunos puntos críticos que deben ser parametrizados en las bio-colecciones con fines de investigación, para garantizar altos estándares de calidad y reproducibilidad en estudios observacionales, en donde se minimice cualquier tipo de sesgo ocasionado por las variables pre-analíticas. Así mismo, identificar la importancia en el desarrollo de biobancos con fines de investigación en nuestro país para contar con material biológico humano de alta calidad.

Palabras Claves: Biobanco, bio-colecciones, variables pre-analíticas, metabolitos, biomarcadores, control de calidad, trazabilidad, material biológico humano.

\begin{abstract}
Human biological material provides valuable information about levels of metabolites associated with the development of certain diseases, becoming an important tool for monitoring responses to treatment or even identifying new intervention mechanisms. The procedures to what the biological material are exposed from their preparation to their analytical phase are called pre-analytical variables, which can have a direct effect on

1. Fundación Cardiovascular de Colombia FCV. Bucaramanga, Colombia.

2. Universidad Autónoma de Bucaramanga UNAB. Bucaramanga, Colombia.

Correspondencia: Norma C. Serrano Díaz. Dirección: Calle 155A No. 23-58. Correo electrónico: normaserrano@fcv.org. Teléfono: +57 6396767 Ext: 214.

Recibido: 23/05/2016

Aprobado: 18/06/2016

Publicado online: $30 / 06 / 2016$
\end{abstract}


the detection of metabolites, and therefore, on the results of the research projects, particularly in the absence of standardized processes that confirm the quality control of the biological material. This technical note highlights some critical points that must be parameterized in the biocollections for research purposes to ensure high standards of quality and reproducibility in observational studies, where any kind of bias caused by the preanalytical variables is minimized. In addition, it is intended to identify the importance of the development of biobanks for research purposes in our country in order to have human biological material of high quality.

Keywords: Biobank, biocollections, pre-analytical variables, metabolites, biomarkers, quality control, traceability, human biological material.

\section{INTRODUCCIÓN}

Los biobancos con fines de investigación biomédica son establecimientos públicos o privados, sin ánimo de lucro, que acogen una o varias colecciones de muestras biológicas de origen humano con fines de investigación, organizados como una unidad técnica con criterios de calidad, orden y destino, independientemente de la finalidad con la que se conserven las muestras ${ }^{1,2}$. Los biobancos además incluyen connotaciones éticas y legales que son relevantes para garantizar los derechos de los participantes (donantes de las muestras) en los proyectos de investigación, temas que han sido abarcados de forma importante en diferentes publicaciones ${ }^{3,4}$. Una de las principales características de estos establecimientos es el desarrollo e implementación de procedimientos operativos estandarizados para garantizar la calidad del material biológico humano (MBH) almacenado 5 .

La mayoría de los biobancos nacieron como biocolecciones por la necesidad de almacenar muestras biológicas remanentes de investigaciones biomédicas o poblacionales, de campañas de salud, o de muestras con propósitos forenses. Posteriormente con los estudios de las ciencias ómicas (genómica, metabolómica, proteómica), quedó expuesta la necesidad de garantizar altos estándares de calidad en un amplio número de muestras, gestionadas al interior de biobancos con fines de investigación que soportaran la realización de estudios a gran escala con rigurosidad técnicocientífica $^{6}$. Diferentes grupos de investigación consideran los biobancos como el punto de partida para cualquier proceso investigativo de generación de nuevo conocimiento, siendo una necesidad para la institución que pretenda establecer un proceso científico a largo plazo, bien sea con fines investigativos, pronósticos o de diagnósticos ${ }^{6,7,8}$.

En la última década, las actividades de los biobancos se han incrementado en cobertura de enfermedades, material biológico, instituciones y redes involucradas a nivel mundial ${ }^{5}$. En Colombia existen diferentes grupos de investigación y entidades que han desarrollado estudios significativos en los cuales se ha logrado incorporar importantes colecciones de $\mathrm{MBH}$, algunos de los cuales han evolucionado con la experiencia, aproximándose a la rigurosidad de los biobancos con fines de investigación. A continuación se nombran algunos de ellos: GenPE -Estudio internacional de genética y pre-eclampsia ${ }^{9}$, Biobanco CARDIECOL -Conocimiento y Acción para Reducir la Dimensión de la Enfermedad Cardiovascular en Colombia ${ }^{10}$, CIDEIM - Biobanco de Centro Internacional de Entrenamiento e Investigaciones Médicas ${ }^{11}$, Neurobanco - Grupo de Neurociencias de la Universidad de Antioquia ${ }^{12}$, Banco Biológico Humano - Instituto de Genética Humana de la Facultad de Medicina de la Pontificia Universidad Javeriana $^{13}$, Banco Nacional de Tumores Terry Fox - Instituto Nacional de Cancerología $-\mathrm{INC}^{14}$ y Red Chagas Colombia ${ }^{15}$.

\section{VARIABLES PRE-ANALÍTICAS}

El MBH proporciona información valiosa sobre la presencia de mutaciones, modificaciones epigenéticas, interacción de genes y proteínas, niveles de metabolitos asociados con el desarrollo de enfermedades, entre otros, convirtiéndose en una herramienta fundamental para la identificación de biomarcadores con fines predictivos, de diagnóstico, para monitoreo de respuestas a tratamientos o incluso para identificar nuevos mecanismo de intervención ${ }^{6}$.

La mala calidad de la muestra, causada por una manipulación incorrecta durante los procesos previos a la detección de un biomarcador, puede producir alteraciones en la expresión génica, degradación del ARN, o variación en los niveles de dicho biomarcador; cambios que pueden iniciar desde el momento cero de la toma de muestra ${ }^{16,17}$. Las variables pre-analíticas se definen como aquellos procedimientos que tienen lugar entre la recolección de muestras y su análisis experimental (momento de la detección o cuantificación 
de metabolitos). Estas variables no deseadas tienen un efecto directo en los resultados, en particular, cuando se utilizan métodos sensibles de cuantificación, generando datos inexactos que pueden comprometer las conclusiones de una investigación. Por lo anterior, se deben tomar medidas previas bajo protocolos estandarizados que garanticen la mayor estabilidad posible para cada muestra según el interés del estudio $\mathrm{y}$, por lo tanto, eviten sesgo $\mathrm{s}^{7,18,19}$.

Las variables pre-analíticas representan de 30 a $75 \%$ de los errores que se reflejan en el proceso analítico ${ }^{20,21}$. Confirmación de esto se muestra en un estudio de Kahn et al. sobre los biomarcadores SCC, (Squamous Cell Carcinoma antigen. CanAG), CEA (Carcinoembrionic Antigen), y CYFRA 21-1, de interés en el monitoreo y pronóstico tumoral. Al identificar una marcada diferencia de dichos marcadores según el momento de la toma de muestra (previa o posterior a la anestesia), y la variación entre extracción venosa y arterial, poniendo en evidencia la importancia de un protocolo estandarizado para la extracción de sangre ${ }^{22}$.

En relación a la calidad del MBH recolectado, los biobancos establecen procedimientos operativos estandarizados para garantizar una alta calidad de las muestras almacenadas y así asegurar que la detección y/o cuantificación de los biomarcadores sea reflejo de un proceso in vivo y no ocasionadas por variables preanalíticas (manipulación ex vivo ${ }^{7}$. En la actualidad no existe un consenso sobre las recomendaciones del manejo de las variables pre-analíticas; sin embargo, algunos biobancos y grupos de investigación han desarrollado y publicado protocolos para controlar su variabilidad ${ }^{23,24}$. El grupo "International Society for Biological and Environmental Repositories Biospecimen Science" desarrolló un sistema de codificación basado en las variables pre-estándar (Standard PREanalytical Code - SPREC), que identifica y registra los principales factores preanalíticos que pueden tener impacto en la integridad de los fluidos corporales y muestras biológicas sólidas así como en sus derivados, durante el proceso de recolección, procesamiento y almacenamiento (Tabla 1) ${ }^{19}$.

Aun así, el impacto sobre la estabilidad de diversos biomarcadores es desconocida. Cuanto más preciso sea el registro de las variables del proceso a lo largo de la vida útil de la muestra, más exhaustiva y extensa es la extracción de información. Las variables preanalíticas se encuentran relacionadas con dos conceptos de calidad de las muestras: su representatividad o capacidad para informar sobre el estado biológico del individuo, y su estabilidad o capacidad para preservar el valor inicial de un metabolito en condiciones definidas ${ }^{7,21}$.

El uso de herramientas automatizadas en los biobancos puede permitir una manipulación eficiente del $\mathrm{MBH}$, con separación de componentes, almacenamiento y recuperación de muestras en poco tiempo bajo condiciones de bajas temperaturas, preservando una mayor cantidad y calidad de metabolitos, pero estos servicios requieren plataformas costosas, implementadas usualmente en servicios centrales. Esto implica que muestras recolectadas fuera de la cobertura del servicio central, estarían expuestas a dificultades en la estandarización del proceso, incorporando variabilidad en las muestras debido a los cambios en la fase pre-analítica. Por esto, el interés internacional alrededor de los biobancos incrementa a medida que disminuye la credibilidad en bio-colecciones que no demuestren altos estándares de calidad ${ }^{7,24}$.

La ejecución de actividades de gestión de calidad requiere dedicación y asignación estratégica de recursos, por lo tanto, es esencial determinar el alcance de la colección del MBH según la naturaleza del proyecto de investigación.

\section{¿Cómo garantizar la calidad en bio-colecciones en proyectos investigación con bajo presupuesto?}

En un país de bajos ingresos como lo es Colombia, donde constantemente surgen nuevos grupos de investigación, pero los recursos para financiar proyectos no son suficientes, es fundamental optimizar dichos recursos en el proceso de planeación, identificando los marcadores de interés, su estabilidad, condiciones necesarias para garantizar una detección y/o cuantificación de alta calidad, entre otros, si se requiere el almacenamiento a largo plazo del $\mathrm{MBH}$. De esta forma, es importante determinar la logística a seguir, estableciendo protocolos que permitan realizar trazabilidad del $\mathrm{MBH}$ incluyendo la recolección o toma de muestra, centrifugación, separación de componentes, condiciones de transporte, temperaturas de exposición, fraccionamiento, almacenamiento temporal y definitivo, fechas, tiempos entre procesos y responsables ${ }^{2,25,26}$.

Entre todas las ciencias "ómicas", la metabolómica es una de las más sensibles a las variables preanalíticas, la reproducibilidad y confiabilidad de los datos analíticos se puede aumentar mediante la validación del método de procesamiento de muestras 
y evaluación de los cambios significativos derivados de la manipulación de muestras no estandarizadas. Para muestras de estudios de genética y epigenética, existen diferentes variables pre-analíticas que también se deben tener en cuenta; por ejemplo, para evitar la degradación de ácidos nucleicos ${ }^{6,18}$, pero estas no se encuentran contempladas en la actual publicación.

Cuando se toma una muestra por flebotomía, la sangre venosa que es baja en oxígeno se introduce en un recipiente vacío en un entorno y temperatura totalmente diferentes a las encontradas in vivo, procedimiento que puede generar cambios significativos ${ }^{1627-29}$. La Figura 1 muestra de forma general aspectos importantes a identificar y controlar en los procesos de manipulación de componentes sanguíneos, para minimizar el impacto de las variables pre-analíticas en la cuantificación y/o detección de metabolitos en proyectos de investigación biomédica, las cuales se describen a continuación.

\section{Identificar la estabilidad de los biomarcadores de interés para el estudio.}

Verificar en la literatura su estabilidad, identificar con qué variables pre-analíticas se afectan y cómo influyen en su cuantificación, aspectos importantes para tener en cuenta en la logística del estudio.

2. Seleccionar la matriz en la que debe ser cuantificado el metabolito (suero, plasma, sangre total, otro).

El plasma y el suero son los materiales biológicos más comunes para la cuantificación de diferentes metabolitos. Más de 4.000 compuestos se encuentran reportados en bases de datos metabólicas, así, según el marcador a estudiar, se deberá establecer en qué matriz (suero o plasma) se cuantificarán ${ }^{30,31}$. Este es un factor importante, aunque algunos artículos mencionan la cuantificación "sérica" de forma indiscriminada para detecciones realizadas en suero o plasma, la diferencia puede ser significativa. Diferentes estudios han demostrado la variación de los niveles medidos en plasma y suero; sin embargo, existe controversia según el metabolito a determinar ${ }^{32-34}$. Por ejemplo, un gran rango de proteínas en tamaño y estructura con una concentración de $60-80 \mathrm{mg} / \mathrm{ml}$ tienen una alta correlación entre el suero y plasma. No obstante las muestras de suero, debido a que carecen de la proteína coagulante, son más valiosas en el diagnóstico clínico y en el seguimiento de una serie de enfermedades ${ }^{30}$.
3. Seleccionar el tubo de recolección (sin anticoagulante, tipo de anticoagulante, con gel, entre otros).

Se deben identificar los tubos recolectores apropiados para los metabolitos que se quieren estudiar: los más comunes son los tubos sin anticoagulante para la obtención de suero y los tubos con anticoagulante EDTA y heparina para plasma y leucocitos; definir el mejor material (vidrio o plástico) y establecer el orden en que se toman los tubos (primero seco, luego con anticoagulante) para evitar interferencias. Algunos tubos contienen gel de barrera que es ampliamente usado para recolección y separación de suero en centros de recolección periférica ${ }^{35,36}$.

\section{Conocer aspectos relevantes en la toma de muestra.}

Algunas variables a tener en cuenta son:

- Preparación previa requerida por parte del participante: estado de ayuno o de dietas específicas, ejercicio físico previo, consumo de medicamentos, alcohol, cigarrillo o alucinógenos, enfermedades recientes diferentes a la del estudio, entre otros ${ }^{26,37}$.

- En el proceso de la toma de muestra sanguínea: aspectos como el calibre de la aguja, movimientos de la aguja, secado del alcohol antes de la flebotomía, la ubicación, presión y tiempo del torniquete, experticia del personal, son aspectos relevantes para evitar hemólisis de la muestra. Las muestras hemolizadas producen diferencias significativas en la cuantificación de metabolitos, por ejemplo, en potasio, fósforo, albúmina y lactato deshidrogenasa ${ }^{38,39}$.

- Posición del participante en el momento de la toma de muestra: es importante conocer si el metabolito a estudiar se ve afectado por la posición o el tiempo de reposo al momento de la toma de muestra, sobre todo en investigaciones que incluyan pacientes hospitalizados. Un estudio realizado por nuestro grupo verificó la variación de homocisteína por variables preanalíticas, en el cual se determinó que este metabolito era altamente reproducible $(\sigma=$ 0,908 , IC95\% 0,861 a 0,955), sin que el ayuno o el tiempo de centrifugación de la muestra afectaran su concentración, pero la posición al momento de la toma de muestra, redujo su concentración hasta en un 20\% (IC95\% 8,4\% a $20,0 \%$ ) en posición de cúbito supino versus la toma en posición sentado ${ }^{40}$. 
5. Establecer la logística para la captación de los participantes y traslado de muestras.

Es primordial identificar si el estudio a realizar contará con captación de participantes en múltiples centros. La captación en un centro específico en donde se realice la toma de muestra, se procese y almacene minimiza el riesgo de variaciones preanalíticas. En contraste, un estudio multicéntrico implica un proceso logístico más complejo que debe contar con protocolos previamente establecidos y realizar capacitación del personal para asegurar la adherencia y normalización de los procesos, tales como, determinar el traslado de muestras, temperatura (ambiente, refrigerada, hielo seco), empresa transportadora, condiciones terrestres o áreas, normativa nacional o internacional, tiempo entre toma de muestra y recepción al centro coordinador determinado por el proyecto. Esto implica una serie de eventos a los que la muestra será sometida y que se deben contemplar antes de la captación del primer participante. Por ejemplo, dependiendo del área de captación, Colombia cuenta con poblaciones de difícil acceso, otras con problemas de orden público; también se deben considerar eventos naturales que pueden obstaculizar el traslado de muestras, eventos religiosos (semana santa), culturales o festividades, que implican una demora en los tiempos de entrega de las empresas transportadoras. Conocer de forma anticipada las rutas e identificar los posibles contratiempos para contar con planes de contingencia, permitirá obtener una mejor calidad del MBH recolectado en estudios multicéntricos ${ }^{2,26,41,42}$.

\section{Centrifugar, separar y fraccionar los componentes}

Las muestras para análisis bioquímico necesitan separarse en el menor tiempo posible para evitar el metabolismo en curso de constituyentes celulares, así como la hemólisis y la fuga de analitos entre el plasma o suero y compartimentos celulares ${ }^{43}$. Algunos estudios han indicado que los valores de la mayoría de los metabolitos son comparables en el suero de mamíferos y de plasma cuando la sangre se toma de forma estandarizada y se realiza separación y fraccionamiento de componentes antes de dos horas, pero como ya se mencionó, puede variar según el metabolito de interés ${ }^{6}$. Así mismo, se debe considerar si es posible realizar la centrifugación bajo refrigeración, porque a temperatura ambiente las reacciones enzimáticas se producen más rápido que a $4^{\circ} \mathrm{C}^{27}$.

7. Almacenar a temperatura adecuada.

A pesar de diversas investigaciones, el ideal de almacenamiento de las muestras de suero y plasma a largo plazo en biobancos queda por determinar. Diferentes estudios han demostrado que el tiempo y la temperatura tienen un efecto importante sobre la estabilidad de los metabolitos $^{44-47}$. Sin embargo, el almacenamiento a $-80{ }^{\circ} \mathrm{C}$ o en nitrógeno líquido ha mostrado una mejor estabilidad para diferentes biomoléculas en suero y plasma ${ }^{34,48,49}$.

Se deben evitar los ciclos de congelación y descongelación porque producen la degradación de proteínas y ácidos nucleicos, por esto es importante fraccionar el $\mathrm{MBH}$, no obstante en ocasiones no existe alternativa debido a la baja disponibilidad de volumen de la muestra. Aunque varios metabolitos en suero o plasma disminuyen por ciclos de congelación-descongelación, estudios realizados por Cuhadar $\mathrm{S}$ et al. y Breier $\mathrm{M}$ et al. demuestran que en dos ciclos de congelación-descongelación de 159 metabolitos investigados, la mayoría son estables a excepción del sulfóxido de metionina ${ }^{34,48}$.

\section{Asegurar la trazabilidad de las muestras.}

Es fundamental contar con protocolos estandarizados para toma de muestra, transporte, separación y fraccionamiento de componentes sanguíneos, y almacenamiento, con el objetivo de disminuir la exposición a variables preanalíticas y normalizar los procedimientos para las muestras recolectadas. Su ejecución y registro con identificación de tiempos, temperaturas y personal responsable de cada proceso, permite una trazabilidad completa del MBH desde su obtención hasta su almacenamiento permanente o salida del estudio (por MBH agotado, cuantificación en otro centro, retiro del consentimiento informado, entre otros). (Ver protocolos previamente publicados Serrano-Díaz N, Páez-Leal MC, Luna-González ML, Guío-Mahecha E. Biobanco Cardiecol. Rev Univ Ind Santander Salud. 2016; 48(2): 95$115)^{2,50}$. 
proyecto por el cual ingresó.

Identificar la estabilidad de los biomarcadores

Seleccionar matriz de cuantificación

Seleccionar tubo de recolección

Conocer aspectos relevantes en la toma de muestra

Establecer logística para captación y traslado de muestras

Centrifugar, separar y fraccionar componentes

Almacenar a temperatura adecuada

Asegurar la trazabilidad de las muestras

Figura 1. Procedimiento operativo estandarizado para la fase pre-analítica del $\mathrm{MBH}$.

Es primordial contar con protocolos y procesos estandarizados para realizar la trazabilidad de las muestras, estipular puntos críticos de control y establecer altos estándares de calidad, para soportar la realización de estudios robustos y reproducibles de asociación entre biomarcadores y una determinada enfermedad, o estudios poblacionales a gran escala en donde se minimice cualquier tipo de sesgo. Así mismo, es importante contar con herramientas computacionales para el monitoreo de las condiciones de conservación del $\mathrm{MBH}$, como de los datos clínicos asociados, una adecuada caracterización, y el aseguramiento de la anonimización del donante. La normalización de procesos puede contribuir al intercambio adecuado de MBH (y la información asociada a este) entre los centros de investigación, permitiendo en un futuro mediato una colaboración que permita optimizar recursos y llegar a resultados más globales ${ }^{2,19,26,41}$.

¿Qué opciones existen para el uso de $\mathrm{MBH}$ previamente recolectado, en el que no se tomaron en cuenta las variables pre-analíticas y se desconoce su trazabilidad?

1. Verificar si el consentimiento informado aplicado al participante inclúa su autorización para el almacenamiento de muestras en estudios futuros, si era específico para determinados metabolitos, o si debió ser descartado al momento de finalizar el
2. Si el participante autorizó el almacenamiento del MBH y su uso para estudios futuros, se deben identificar los biomarcadores de interés, de lo contrario las muestras deben ser descartadas siguiendo las normas de bioseguridad y generar el acta correspondiente

3. Verificar la estabilidad de los biomarcadores de interés. Existen metabolitos que son estables frente a diferentes variables pre-analíticas. En el material complementario (Tabla 1S), se incluye la revisión sistemática de la literatura sobre el impacto de las variables pre-analíticas como ciclos de congelación-descongelación, tiempo y temperatura de almacenamiento en algunos biomarcadores de interés en riesgo cardiovascular: IL-1, IL-6, TNF $\alpha$, CRP, Vitamina D, adiponectina, leptina y cistatina $\mathrm{C}$ en muestras de suero y plasma. Si el biomarcador de interés presenta una alta estabilidad frente a variables pre-analíticas, se incrementa su viabilidad y potencial uso. Pero sin conocer su estabilidad, ni la trazabilidad en las muestras, continuará la incertidumbre y por ende, la posibilidad de sesgo en determinación e interpretación de resultados.

4. Si las muestras almacenadas son fundamentales y como en muchos estudios irrecuperables, por ejemplo debido al momento específico de la captación en determinada patología, y si el volumen lo permite, el uso de biomarcadores conocidos por su estabilidad o degradación bajo determinadas variables pre-analíticas puede ser un elemento de utilidad para inferir qué muestras pueden ser incorporadas en el estudio de metabolitos específicos.

En el estudio realizado por Jean-Pierre Trezzi, et al., teniendo como punto de partida el metabolismo celular, identificaron un marcador para el control de las condiciones de pre-centrifugación en plasma que denominaron LacaScore, basados en la relación del ácido ascórbico y el ácido láctico en plasma ${ }^{27}$. $\mathrm{El}$ ácido ascórbico se degrada rápidamente debido a la oxidación y/o transformación a oxalato y se ha demostrado que existe mayor estabilidad en muestras almacenadas a $-80^{\circ} \mathrm{C}^{51,52}$. Por otra parte, los eritrocitos producen energía por medio de la glicólisis dando lugar a la producción de ácido láctico que se acumula rápidamente en las células y se excreta en el plasma ${ }^{27,53,54}$.

En el material suplementario (Tabla 2S), se presenta una revisión realizada en la literatura sobre posibles biomarcadores para uso como controles de calidad de MBH almacenado. 
Tabla 1. Variables pre-analíticas incluidas en el SPREC, aplicable a fluidos corporales.

\begin{tabular}{|c|c|}
\hline Variable & Opciones \\
\hline Tipo de muestra & $\begin{array}{l}\text { Líquido amniótico } \\
\text { Sangre (completa) } \\
\text { Líquido cefalorraquídeo } \\
\text { Líquido pleural } \\
\text { Suero } \\
\text { Plasma } \\
\text { Líquido sinovial } \\
\text { Orina } \\
\text { Otros }\end{array}$ \\
\hline Tipo de contenedor primario & $\begin{array}{l}\text { Tubo al vacío / citrato o equivalente } \\
\text { Tubo al vacío / heparina o equivalente } \\
\text { Tubo al vacío / EDTA o equivalente } \\
\text { Tubo estéril de polipropileno } \\
\text { Tubos para estabilización y aislamiento de ARN } \\
\text { Tubos para detección de trazas de metales } \\
\text { Tubo seco } \\
\text { Tubo con gel }\end{array}$ \\
\hline Retardo entre recolección y procesamiento de la muestra & $\begin{array}{l}\mathrm{T} \text { ambiente }<2 \mathrm{~h} \\
\text { Entre } 3-7^{\circ} \mathrm{C}<2 \mathrm{~h} \\
\mathrm{~T} \text { ambiente }\left(20^{\circ} \mathrm{C}+/-2{ }^{\circ} \mathrm{C}\right) \text { por } 2-4 \mathrm{~h} \\
\text { Entre } 3-7^{\circ} \mathrm{C} \text { por } 2-4 \mathrm{~h} \\
\mathrm{~T} \text { ambiente } \mathrm{x} 4-8,8-12,12-24,24-48 \mathrm{y}>48 \mathrm{~h} \\
\text { Entre } 3-7^{\circ} \mathrm{C} \times 4-8,8-12,12-24,24-48 \mathrm{y}>48 \mathrm{~h} \\
\text { Desconocido }\end{array}$ \\
\hline Centrifugación inicial & $\begin{array}{l}\mathrm{T} \text { ambiente } \times 10 \mathrm{mn} \text { a } 3.000 \mathrm{~g} \text { sin freno } \\
\mathrm{T} \text { ambiente } \times 10 \mathrm{mn} \text { a } 3.000 \mathrm{~g} \text { con freno } \\
3-7^{\circ} \mathrm{C} \times 10 \mathrm{mn} \text { a } 3.000 \mathrm{~g} \text { sin freno } \\
3-7^{\circ} \mathrm{C} \times 10 \mathrm{mn} \text { a } 3.000 \mathrm{~g} \text { con freno } \\
\mathrm{T} \text { ambiente } \times 10 \mathrm{mn} \text { a } 3.000-6.000 \mathrm{~g} \text { sin freno } \\
\mathrm{T} \text { ambiente } \times 10 \mathrm{mn} \text { a } 3.000-6.000 \mathrm{~g} \text { con freno } \\
3-7^{\circ} \mathrm{C} \times 10 \mathrm{mn} \text { a } 3.000-6.000 \mathrm{~g} \text { sin freno } \\
3-7^{\circ} \mathrm{C} \times 10 \mathrm{mn} \text { a } 3.000-6.000 \mathrm{~g} \text { con freno } \\
\text { Sin centrifugación } \\
\text { Desconocido }\end{array}$ \\
\hline Segunda centrifugación & $\begin{array}{l}\text { Iguales opciones a la anterior especificando que es el segundo } \\
\text { procedimiento }\end{array}$ \\
\hline Retraso post-centrifugación & $\begin{array}{l}<1 \mathrm{~h} \text { entre } 3-7^{\circ} \mathrm{C} \\
<1 \mathrm{~h} \text { a T ambiente } \\
1-2 \mathrm{~h} \text { entre } 3-7^{\circ} \mathrm{C} \\
1-2 \mathrm{~h} \text { a T ambiente } \\
2-8 \mathrm{~h} \text { entre } 3-7^{\circ} \mathrm{C} \\
2-8 \mathrm{~h} \text { a T ambiente } \\
8-24 \mathrm{~h} \text { entre } 3-7^{\circ} \mathrm{C} \\
>24 \mathrm{~h} \text { a T ambiente } \\
>24 \mathrm{~h} \text { entre } 3-7^{\circ} \mathrm{C} \\
\text { Desconocido }\end{array}$ \\
\hline Condiciones de almacenamiento a largo plazo & $\begin{array}{l}\text { Tubos de polipropileno } 0,5-2 \mathrm{ml} \text { a }-85 \text { y }-60{ }^{\circ} \mathrm{C} \\
\text { Tubos de polipropileno } 0,5-2 \mathrm{ml} \text { a }-35 \text { y }-18{ }^{\circ} \mathrm{C} \\
\text { Criotubos } 1-2 \mathrm{ml} \text { en nitrógeno líquido } \\
\text { Criotubos } 1-2 \mathrm{ml} \text { a }-85 \text { y }-60{ }^{\circ} \mathrm{C} \\
\text { Tubos de polipropileno } \geq 5 \mathrm{ml} \mathrm{a}-85 \text { y }-60{ }^{\circ} \mathrm{C} \\
\text { Tubos de polipropileno } \geq 5 \mathrm{ml} \mathrm{a}-35 \text { y }-18{ }^{\circ} \mathrm{C} \\
\text { Pajilla en nitrógeno líquido } \\
\text { Pajilla a }-85 \text { y }-60{ }^{\circ} \mathrm{C} \\
\text { Pajilla a }-35 \text { y }-18{ }^{\circ} \mathrm{C} \\
\text { Microplato a }-85 \text { y }-60{ }^{\circ} \mathrm{C} \\
\text { Microplato a }-35 \text { y }-18{ }^{\circ} \mathrm{C} \\
\text { Otro }\end{array}$ \\
\hline
\end{tabular}

Adaptado de Betsou F, et al. Standard preanalytical coding for biospecimens: defining the sample PREanalytical code ${ }^{19}$. 


\section{CONCLUSIONES}

Las variables pre-analíticas son parte esencial en la identificación y/o cuantificación de biomarcadores pero muchas veces son sub-estimadas. Aunque los aspectos descritos en este artículo implican una mayor inversión de tiempo en el diseño de protocolos, pueden llevar a una mejor optimización de los recursos y lo que es más importante, generar resultados válidos, robustos y reproducibles. Las diferencias ocasionadas por procesos inherentes a variables pre-analíticas pueden comprometer la credibilidad de los resultados obtenidos en estudios de investigación relevantes.

Para estudios futuros es primordial promover el desarrollo de biobancos con fines de investigación en nuestro país, que permitan contar con MBH de alta calidad para estudios secundarios. En consecuencia, para dar cumplimiento, se requiere un marco regulatorio y legislativo que abarque los aspectos éticos y legales, así como la armonización de las normas y procedimientos técnico-científicos a utilizar que garanticen contar con MBH de la calidad requerida para obtener resultados válidos.

\section{AGRADECIMIENTOS}

Apoyos Recibidos: Colciencias bajo el contrato 6962014, Programa CARDIECOL, Código 617399847755. El Biobanco CARDIECOL, como unidad estructural del programa, que tiene como objetivo diseñar y desarrollar una plataforma biológica con población colombiana, adulta e infantil, para el estudio de factores de riesgo convencionales y no convencionales (genéticos) en enfermedad cardiovascular. Esta plataforma biológica con fines de investigación se encuentra asociada con la Unidad de Datos del programa, la cual se encarga del manejo de datos clínicos electrónicos vinculados al material biológico almacenado.

Joven investigador Colciencias contrato No 0262 de 2014, dentro de este marco se desarrolló el material suplementario del presente artículo.

\section{REFERENCIAS}

1. Real Decreto 1716/2011, de 18 de noviembre, por el que se establecen los requisitos básicos de autorización y funcionamiento de los biobancos con fines de investigación biomédica y del tratamiento de las muestras biológicas de origen humano, y se regula el funcionamiento y organización del Registro Nacional de Biobancos para investigación biomédica.

2. Serrano-Díaz N, Páez-Leal MC, Luna-González ML, Guío-Mahecha E. Biobanco: Herramienta fundamental para la investigación biomédica actual. Rev Univ Ind Santander Salud. 2016; 48(1): 97-117.

3. Cabrera LA, Wiesner C, Serrano ML, Peñaranda Correa NR, Huertas A. Consideraciones éticas y legales de los biobancos para investigación. Rev Col Bioética. 2010; 5(1): 121-141.

4. Nemogá-Soto GR. Pensamiento Jurídico, No. 35, septiembre-diciembre, Bogotá, 2012, p. 195-230.

5. Mora M, Angelini C, Bignami F, Bodin AM, Crimi M, Di Donato JH, et al. The EuroBioBank Network: 10 years of hands-on experience of collaborative, transnational biobanking for rare diseases. Eur J Hum Genet. 2015; 23(9): 1116-1123. DOI: 10.1038/ ejhg.2014.272.

6. Mohamadkhani A, Poustchi H. Repository of Human Blood Derivative Biospecimens in Biobank: Technical Implications. Middle East J Dig Dis. 2015; 7(2): 61-68.

7. Neururer SB, Hofer P, Göbel G. An IT-Supported Evaluation Tool for Biobanks Based on International Guidelines to Improve the Biosample Quality. Stud Health Technol Inform. 2016; 223: 46-53.

8. Martínez JC, Briceño I, Hoyos A, Gómez A. Biobancos. Una estrategia exigente y esencial para la conservación de muestras biológicas. Act Med Colomb.2012; 37(3): 158-162.

9. Estudio internacional de genética y preeclampsia GenPE.

10. Conocimiento y acción para reducir la dimensión de la enfermedad cardiovascular en Colombia CARDIECOL.

11. Centro internacional de entrenamiento e investigaciones médicas CIDEIM.

12. Neurobanco del Grupo de Neurociencias de la Universidad de Antioquia.

13. Gómez A. Banco Biológico Humano. Instituto de Genética Humana. Rev Javeriana 1992; 586: 9-11.

14. Red de institutos e instituciones nacionales de Cáncer RINC. Instituto nacional de cancerología (INC). Banco Nacional de Tumores Terry Fox.

15. Red Chagas Colombia. www.redchagascolombia. org/centro-de-control-de-datos-y-muestras-redchagas.

16. Baechler EC, Batliwalla FM, Karypis G, Gaffney PM, Moser K, Behrens TW, et al. Expression levels for many genes in human peripheral blood cells are highly sensitive to ex vivo incubation. Genes Immun. 2004; 5(5): 347-353.

17. Pahl A, Brune K. Stabilization of gene expression profiles in blood after phlebotomy. Clin Chem. 
2002; 48(12): 2251-2253.

18. Zhang H, Korenková V, Sjöback R, Švec D, Björkman J, Kruhøffer M, et al. Biomarkers for monitoring pre-analytical quality variation of mRNA in blood samples. PLoS One. 2014; 9(11): e111644. DOI: http://dx.doi.org/10.1371/journal. pone. 0111644.

19. Betsou F, Lehmann S, Ashton G, Barnes M, Benson EE, Gunter E, et al; International Society for Biological and Environmental Repositories (ISBER) Working Group on Biospecimen Science. Standard preanalytical coding for biospecimens: defining the sample PREanalytical code. Cancer Epidemiol Biomarkers Prev. 2010; 19(4): 10041011. DOI: 10.1158/1055-9965.EPI-09-1268.

20. Kaushik N, Green S. Pre-analytical errors: their impact and how to minimize them. MLO Med Lab Obs. 2014; 46(5): 22, 24-26.

21. Simundic AM, Lippi G. Preanalytical phase--a continuous challenge for laboratory professionals. Biochem Med (Zagreb). 2012; 22(2): 145-149.

22. Kahn N, Riedlinger J, Roeßler M, Rabe C, Lindner $\mathrm{M}$, Koch I, et al. Blood-sampling collection prior to surgery may have a significant influence upon biomarker concentrations measured. Clin Proteomics. 2015; 12(1): 19. DOI: 10.1186/s12014015-9093-6.

23. Holland NT, Pfleger L, Berger E, Ho A, Bastaki M. Molecular epidemiology biomarkers--sample collection and processing considerations. Toxicol Appl Pharmacol. 2005; 206(2): 261-268.

24. Holland NT, Smith MT, Eskenazi B, Bastaki M. Biological sample collection and processing for molecular epidemiological studies. Mutat Res. 2003; 543(3): 217-234.

25. Vaught J, Abayomi A, Peakman T, Watson P, Matzke L, Moore H. Critical issues in international biobanking. Clin Chem. 2014; 60(11): 1368-1374. DOI: $10.1373 /$ clinchem.2014.224469.

26. Ellervik C, Vaught J. Preanalytical variables affecting the integrity of human biospecimens in biobanking. Clin Chem. 2015; 61(7): 914-934. DOI: 10.1373/clinchem.2014.228783.

27. Trezzi JP, Bulla A, Bellora C, Rose M, Lescuyer P, Kiehntopf M, et al. LacaScore: a novel plasma sample quality control tool based on ascorbic acid and lactic acid levels. Metabolomics. 2016; 12: 96. DOI: 10.1007/s11306-016-1038-1.

28. Lippi G, Chance JJ, Church S, Dazzi P, Fontana R, Simundic AM, et al. Preanalytical quality improvement: from dream to reality. Clin Chem Lab Med. 2011; 49(7): 1113-1126. DOI: 10.1515/ CCLM.2011.600.
29. Lippi G, Guidi GC. Risk management in the preanalytical phase of laboratory testing. Clin Chem Lab Med. 2007; 45(6): 720-727.

30. Barelli S, Crettaz D, Thadikkaran L, Rubin O, Tissot JD. Plasma/serum proteomics: pre-analytical issues. Expert Rev Proteomics. 2007; 4(3): 363-370.

31. The Human Metabolome Database. www.hmdb.ca.

32. Yatomi Y, Igarashi Y, Yang L, Hisano N, Qi R, Asazuma N, et. al. Sphingosine 1-phosphate, a bioactive sphingolipid abundantly stored in platelets, is a normal constituent of human plasma and serum. J Biochem. 1997; 121(5): 969-973.

33. Ishikawa M, Maekawa K, Saito K, Senoo Y, Urata M, Murayama M, et al. Plasma and serum lipidomics of healthy white adults shows characteristic profiles by subjects' gender and age. PLoS One. 2014 Mar 14; 9(3): e91806. DOI: 10.1371/journal.pone.0091806.

34. Breier M, Wahl S, Prehn C, Fugmann M, Ferrari U, Weise $\mathrm{M}$, et al. Targeted metabolomics identifies reliable and stable metabolites in human serum and plasma samples. PLoS One. 2014; 9(2): e89728. DOI: http://dx.doi.org/10.1371/journal. pone. 0089728 .

35. Tanner M, Kent N, Smith B, Fletcher S, Lewer M. Stability of common biochemical analytes in serum gel tubes subjected to various storage temperatures and times pre-centrifugation. Ann Clin Biochem. 2008; 45(Pt 4): 375-379. DOI: 10.1258/ acb.2007.007183.

36. Cuhadar S, Atay A, Koseoglu M, Dirican A, Hur A. Stability studies of common biochemical analytes in serum separator tubes with or without gel barrier subjected to various storage conditions. Biochem Med (Zagreb). 2012; 22(2): 202-214.

37. Kaushik N, Green S. Pre-analytical errors: their impact and how to minimize them. MLO Med Lab Obs. 2014; 46(5):22, 24, 26.

38. Rossing RG, Foster DM. The stability of clinical chemistry specimens during refrigerated storage for 24 hours. Am J Clin Pathol. 1980; 73(1): 91-95.

39. Condelli V, Lettini G, Patitucci G, D'Auria F, D'Amico M, Vita G, et al. Validation of vacuumbased refrigerated system for biobanking tissue preservation: analysis of cellular morphology, protein stability, and RNA quality. Biopreserv Biobank. 2014; 12(1): 35-45. DOI: 10.1089/ bio.2013.0065.

40. Serrano NC, Páez MC, Bautista PK, Díaz LA, Guío E. Variables pre-analíticas que afectan las concentraciones de homocisteína: Aplicación para Biobancos con fines de investigación. Med UNAB. 2013; 16(2): 59-64.

41. Riondino S, Ferroni P, Spila A, Alessandroni J, 
D’Alessandro R, Formica V, et al. Ensuring Sample Quality for Biomarker Discovery Studies - Use of ICT Tools to Trace Biosample Life-cycle. Cancer Genomics Proteomics. 2015; 12(6): 291-299.

42. Berg B, Estborn B, Tryding N. Stability of serum and blood constituents during mail transport. Scand J Clin Lab Invest. 1981; 41(5): 425-430.

43. Taylor EC, Sethi B. Stability of 27 biochemistry analytes in storage at a range of temperatures after centrifugation. Br J Biomed Sci. 2011; 68(3): 147-157.

44. Gislefoss RE, Grimsrud TK, Mørkrid L. Stability of selected serum proteins after long-term storage in the Janus Serum Bank. Clin Chem Lab Med. 2009; 47(5): 596-603. DOI: 10.1515/CCLM.2009.121.

45. Nilsson TK, Boman K, Jansson JH, Thøgersen AM, Berggren M, Broberg A, et al. Comparison of soluble thrombomodulin, von Willebrand factor, tPA/PAI-1 complex, and high-sensitivity CRP concentrations in serum, EDTA plasma, citrated plasma, and acidified citrated plasma (Stabilyte) stored at -70 degrees C for 8-11 years. Thromb Res. 2005; 116(3): 249-254.

46. Ishikawa S, Kayaba K, Gotoh T, Nakamura Y, Kario K, Ito Y, et al. Comparison of C-reactive protein levels between serum and plasma samples on long-term frozen storage after a 13.8 year interval: the JMS Cohort Study. J Epidemiol. 2007; 17(4): 120-124.

47. Zander J, Bruegel M, Kleinhempel A, Becker S, Petros $\mathrm{S}$, Kortz L, et al. Effect of biobanking conditions on short-term stability of biomarkers in human serum and plasma. Clin Chem Lab Med. 2014; 52(5): 629639. DOI: $10.1515 / \mathrm{cclm}-2013-0705$.

48. Cuhadar S, Koseoglu M, Atay A, Dirican A. The effect of storage time and freeze-thaw cycles on the stability of serum samples. Biochem Med (Zagreb). 2013; 23(1): 70-77.

49. Hartweg J, Gunter M, Perera R, Farmer A, Cull C, Schalkwijk C, et al. Stability of soluble adhesion molecules, selectins, and C-reactive protein at various temperatures: implications for epidemiological and large-scale clinical studies. Clin Chem. 2007; 53(10): 1858-60.

50. Serrano-Díaz N, Guío-Mahecha E, Páez-Leal MC. Consentimiento informado para Biobancos: Un debate abierto. Rev Univ Ind Santander Salud. 2016; 48(2): 246-256.

51. Wilson DM, Liedtke RR. Modified enzymebased colorimetric assay of urinary and plasma oxalate with improved sensitivity and no ascorbate interference: reference values and sample handling procedures. Clin Chem. 1991; 37(7): 1229-1235.

52. Spínola V, Llorent-Martínez EJ, Castilho PC.
Determination of vitamin $\mathrm{C}$ in foods: current state of method validation. J Chromatogr A. 2014; 1369: 2-17. DOI: 10.1016/j.chroma.2014.09.087.

53. Simchowitz L, Textor JA. Lactic acid secretion by human neutrophils. Evidence for an $\mathrm{H}++$ lactatecotransport system. J Gen Physiol. 1992; 100(2): 341-367.

54. De Bruijne AW, Vreeburg H, Van Steveninck J. Kinetic analysis of L-lactate transport in human erythrocytes via the monocarboxylate-specific carrier system. Biochim Biophys Acta. 1983; 732(3): 562-568. 


\section{Material suplementario}

\section{IMPACTO DE LAS VARIABLES PRE-ANALÍTCAS EN LA ESTABILIDAD DE BIOMARCADORES DE INTERÉS CARDIOVASCULAR}

Objetivo: Describir los reportes evidenciados en la literatura sobre el impacto de las variables pre-analíticas; ciclos de congelación, tiempo y temperatura de almacenamiento, en la estabilidad de los biomarcadores IL-1, IL-6, TNF-a, CRP, MICA, adiponectina, leptina, cistatina C y vitamina D.

Metodología: Los artículos incluidos en la tabla 1S, se obtuvieron de las bases de datos PUBMED y BVS con los términos DECs y MeSH de los biomarcadores y variables de interés.

Resultados: Se analizaron 40 artículos que cumplieron con los criterios de inclusión. IL-6, cistatina C y CRP son estables durante varios ciclos de congelación y por largos periodos de almacenamiento. TNF-a es estable en muestras almacenadas entre $-70^{\circ}$ y $-80^{\circ} \mathrm{C}$, mientras disminuye en muestras almacenadas a temperatura ambiente y $-4^{\circ} \mathrm{C}$. Un número limitado de artículos evalúan el impacto de las variables pre-analíticas consideradas, en la estabilidad de la adiponectina y leptina y no se encontraron reportes sobre el impacto de estas variables en la estabilidad del biomarcador MICA.

Conclusión: Los resultados de los artículos que se describen en la tabla $2 \mathrm{~S}$ orientan la planeación y el diseño de estudios epidemiológicos, y aportan información valiosa para la elección de sistemas de almacenamiento adecuados y la interpretación de datos obtenidos a partir de muestras almacenadas en Biobancos con fines de investigación.

Tabla 1S. Impacto de las variables pre-analíticas de ciclos de descongelación, tiempo y temperatura de almacenamiento en biomarcadores de interés en Enfermedad cardiovascular

\begin{tabular}{|c|c|c|c|c|c|}
\hline \multirow[b]{2}{*}{ Analito } & \multirow[b]{2}{*}{ Resultado } & \multicolumn{2}{|c|}{ Característica Variable } & \multirow{2}{*}{$\begin{array}{l}\text { Unidad de } \\
\text { cambio }\end{array}$} & \multirow[b]{2}{*}{ Ref } \\
\hline & & Tiempo/Ciclos & $\begin{array}{l}\text { Temperatura } \\
\left({ }^{\circ} \mathrm{C}\right)\end{array}$ & & \\
\hline \multirow{4}{*}{ CRP(hs) } & Estable & $11 \mathrm{~A}$ & -70 & 0 & $\begin{array}{l}\text { Doumatey AP, et al. Clin Biochem. 2014; 47(4-5):315-8. } \\
\text { Nilsson TK, et al. Thromb Res. 2005; 116(3): 249-254. }\end{array}$ \\
\hline & Estable & $05 \mathrm{D}$ & Ambiente & 0 & Hartweg J, et al. Clin Chem. 2007; 53(10): 1858-1860. \\
\hline & Estable & $05 \mathrm{C}$ & -80 & 0 & Hartweg J, et al. Clin Chem. 2007; 53(10): 1858-1860. \\
\hline & Inestable & $13 \mathrm{~A}$ & -80 & $\begin{array}{l}\text { Aumento } \\
28 \% *\end{array}$ & Ishikawa S, et al. J Epidemiol. 2007; 17(4): 120-124. \\
\hline \multirow{9}{*}{ CRP } & Estable & $02 \mathrm{~A}$ & -80 & 0 & Gu Y, et al. Cytokine. $2009 ;$ 45(1): 44-49. \\
\hline & Estable & $12 \mathrm{~A}$ & -80 & 0 & Hardikar S, et al. Cancer Causes Control. 2014; 25(8): 969-176. \\
\hline & Estable & $03 \mathrm{M}$ & -70 & 0 & $\begin{array}{l}\text { Castellanos Y, et al. Rev Univ Ind Santander Salud. 2012; } \\
\text { 44(3): } 25-30 \text {. }\end{array}$ \\
\hline & Estable & $21 \mathrm{D}$ & -04 & 0 & $\begin{array}{l}\text { Aziz N, et al. Clin Diagn Lab Immunol. 2003; 10(4): } 652- \\
657 .\end{array}$ \\
\hline & Estable & $21 \mathrm{D}$ & -20 & 0 & $\begin{array}{l}\text { Aziz N, et al. Clin Diagn Lab Immunol. 2003; 10(4): 652- } \\
657 .\end{array}$ \\
\hline & Estable & $21 \mathrm{D}$ & -70 & 0 & $\begin{array}{l}\text { Aziz N, et al. Clin Diagn Lab Immunol. 2003; 10(4): } 652- \\
657 .\end{array}$ \\
\hline & Estable & $24 \mathrm{H}$ & Ambiente & 0 & Tanner M, et al. Ann Clin Biochem. 2008; 45(Pt 4): 375-379. \\
\hline & Estable & $10 \mathrm{C}$ & -70 & 0 & $\begin{array}{l}\text { Aziz N, et al. Clin Diagn Lab Immunol. 2003; 10(4): 652- } \\
657 .\end{array}$ \\
\hline & Estable & $09 \mathrm{C}$ & -196 & 0 & Kang HJ, et al. Biopreserv Biobank. 2013; 11(2): 94100. \\
\hline
\end{tabular}




\begin{tabular}{|c|c|c|c|c|c|}
\hline \multirow[b]{2}{*}{ Analito } & & \multicolumn{2}{|c|}{ Característica Variable } & \multirow{2}{*}{$\begin{array}{l}\text { Unidad de } \\
\text { cambio }\end{array}$} & \multirow[b]{2}{*}{ Ref } \\
\hline & & Tiempo/Ciclos & $\begin{array}{l}\text { Temperatura } \\
\left({ }^{\circ} \mathrm{C}\right)\end{array}$ & & \\
\hline \multirow{16}{*}{ TNF-a } & Estable & $03 \mathrm{~A}$ & -80 & 0 & De Jager W, et al. BMC Immunol. 2009; 10: 52. \\
\hline & Estable & $02 \mathrm{~A}$ & -80 & 0 & Gu Y, et al. Cytokine. 2009; 45(1): 44-49. \\
\hline & Estable & $04 \mathrm{M}$ & -70 & 0 & Exley AR, et al. Cytokine. 1990; 2(5): 353-356. \\
\hline & Estable & $03 \mathrm{M}$ & -20 & 0 & Zander J, et al. Clin Chem Lab Med. 2014; 52(5): 629-639. \\
\hline & Estable & $03 \mathrm{M}$ & -80 & 0 & Zander J, et al. Clin Chem Lab Med. 2014; 52(5): 629-639. \\
\hline & Estable & $20 \mathrm{D}$ & -70 & 0 & Aziz N, et al. Clin Diagn Lab Immunol. 1999; 6(1): 89-95. \\
\hline & Estable & $24 \mathrm{H}$ & -04 & 0 & $\begin{array}{l}\text { Friebe A, et al. Arch Pathol Lab Med. 2008; 132(11):1802- } \\
1806 .\end{array}$ \\
\hline & Estable & $24 \mathrm{H}$ & -20 & 0 & $\begin{array}{l}\text { Friebe A, et al. Arch Pathol Lab Med. 2008; 132(11): 1802- } \\
1806 .\end{array}$ \\
\hline & Estable & $24 \mathrm{H}$ & -70 & 0 & $\begin{array}{l}\text { Friebe A, et al. Arch Pathol Lab Med. 2008; 132(11): 1802- } \\
1806 .\end{array}$ \\
\hline & Estable & $10 \mathrm{C}$ & -80 & 0 & $\begin{array}{l}\text { Aziz N, et al. Clin Diagn Lab Immunol. 1999; 6(1): 89-95 } \\
\text { Guo GH, et al. Mol Med Rep. 2013; 7(3): 775-780. }\end{array}$ \\
\hline & Estable & $06 \mathrm{C}$ & -04 & 0 & $\begin{array}{l}\text { Thavasu PW, et al. J Immunol Methods. 1992; 153(1-2): } \\
\text { 115-124. }\end{array}$ \\
\hline & Estable & $03 \mathrm{C}$ & -80 & 0 & Hosnijeh FS, et al. Biomarkers. 2010; 15(2): 140-148. \\
\hline & Inestable & $03 \mathrm{C}$ & -70 & $\begin{array}{c}\text { Aumento } \\
4.1 \%\end{array}$ & Flower L, et al. Cytokine. 2000; 12(11): 1712-1716. \\
\hline & Inestable & $01 \mathrm{C}$ & -80 & $\begin{array}{c}\text { Aumento } \\
10 \%\end{array}$ & De Jager W, et al. BMC Immunol. 2009; 10: 52. \\
\hline & Inestable & $03 \mathrm{M}$ & 04 & $\begin{array}{c}\text { Disminución } \\
96 \%\end{array}$ & Zander J, et al. Clin Chem Lab Med. 2014; 52(5): 629-639. \\
\hline & Inestable & $03 \mathrm{D}$ & Ambiente & $\begin{array}{l}\text { Disminución } \\
2.8 \%\end{array}$ & Aziz N, et al. Clin Diagn Lab Immunol. 1999; 6(1): 89-95 \\
\hline \multirow{12}{*}{ IL-6 } & Estable & $12 \mathrm{~A}$ & -80 & 0 & $\begin{array}{l}\text { Hardikar S, et al. Cancer Causes Control. 2014; 25(8): 969- } \\
976 .\end{array}$ \\
\hline & Estable & $02 \mathrm{~A}$ & -80 & 0 & Gu Y, et al. Cytokine. 2009; 45(1): 44-49. \\
\hline & Estable & $03 \mathrm{M}$ & -70 & 0 & $\begin{array}{l}\text { Castellanos Y, et al. Rev Univ Ind Santander Salud UIS. } \\
\text { 2012, 44(3): 25-30. }\end{array}$ \\
\hline & Estable & $21 \mathrm{D}$ & -04 & 0 & Kenis G, et al. Cytokine. 2002; 19(5): 228-235. \\
\hline & Estable & $21 \mathrm{D}$ & -20 & 0 & Kenis G, et al. Cytokine. 2002; 19(5): 228-235. \\
\hline & Estable & $72 \mathrm{H}$ & -04 & 0 & $\begin{array}{l}\text { Mechanic L, et al. Clin Chem Lab Med. 2013; 51(12): 2287- } \\
2294 .\end{array}$ \\
\hline & Estable & $24 \mathrm{H}$ & -04 & 0 & $\begin{array}{l}\text { Friebe A, et al. Arch Pathol Lab Med. 2008; 132(11): 1802- } \\
1806 .\end{array}$ \\
\hline & Estable & $24 \mathrm{H}$ & -20 & 0 & $\begin{array}{l}\text { Friebe A, et al. Arch Pathol Lab Med. 2008; 132(11): 1802- } \\
1806 .\end{array}$ \\
\hline & Estable & $10 \mathrm{C}$ & -80 & 0 & Guo GH, et al. Mol Med Rep. 2013; 7(3): 775-780 \\
\hline & Estable & $06 \mathrm{C}$ & -70 & 0 & Flower L, et al. Cytokine. 2000; 12(11): 1712-1716. \\
\hline & Estable & $04 \mathrm{C}$ & -20 & 0 & $\begin{array}{l}\text { De Jager W, et al. BMC Immunol. 2009; 10: } 52 . \\
\text { Kenis G, et al. Cytokine. 2002; 19(5): 228-235. }\end{array}$ \\
\hline & Estable & $03 \mathrm{C}$ & -04 & 0 & $\begin{array}{l}\text { Thavasu PW, et al. J Immunol Methods. 1992; 153(1-2): } \\
\text { 115-124. }\end{array}$ \\
\hline
\end{tabular}




\begin{tabular}{|c|c|c|c|c|c|}
\hline \multirow[b]{2}{*}{ Analito } & \multirow[b]{2}{*}{ Resultado } & \multicolumn{2}{|c|}{ Característica Variable } & \multirow{2}{*}{$\begin{array}{l}\text { Unidad de } \\
\text { cambio }\end{array}$} & \multirow[b]{2}{*}{ Ref } \\
\hline & & Tiempo/Ciclos & $\begin{array}{l}\text { Temperatura } \\
\left({ }^{\circ} \mathrm{C}\right)\end{array}$ & & \\
\hline \multirow{4}{*}{ IL-1a } & Estable & $06 \mathrm{M}$ & -04 & 0 & Guo GH, et al. Mol Med Rep. 2013; 7(3): 775-780 \\
\hline & Estable & $06 \mathrm{C}$ & -04 & 0 & $\begin{array}{l}\text { Thavasu PW, et al. J Immunol Methods. 1992; 153(1-2): } \\
\text { 115-124. }\end{array}$ \\
\hline & Estable & $10 \mathrm{C}$ & -80 & 0 & Guo GH, et al. Mol Med Rep. 2013; 7(3): 775-780 \\
\hline & Inestable & $02 \mathrm{~A}$ & -80 & $\begin{array}{c}\text { Disminución } \\
10 \%\end{array}$ & De Jager W, et al. BMC Immunol. 2009; 10: 52. \\
\hline \multirow{4}{*}{ IL-1b } & Estable & $06 \mathrm{M}$ & -04 & 0 & Guo GH, et al. Mol Med Rep. 2013; 7(3): 775-780 \\
\hline & Estable & $06 \mathrm{C}$ & -04 & 0 & $\begin{array}{l}\text { Thavasu PW, et al. J Immunol Methods. 1992; 153(1-2): } \\
\text { 115-124. }\end{array}$ \\
\hline & Estable & $03 \mathrm{C}$ & -80 & 0 & Hosnijeh FS, et al. Biomarkers. 2010; 15(2): 140-148. \\
\hline & Inestable & $02 \mathrm{~A}$ & -80 & $\begin{array}{l}\text { Disminución } \\
25 \%\end{array}$ & De Jager W, et al. BMC Immunol. 2009; 10: 52. \\
\hline \multirow{4}{*}{ Adiponectina } & Estable & $01 \mathrm{~A}$ & -196 & 0 & Pischon T, et al. Clin Chem. 2003; 49(4): 650-652. \\
\hline & Estable & $30 \mathrm{M}$ & -30 & 0 & Shand B, et al. Chem Lab Med. 2006; 44(10): 1264-1268. \\
\hline & Estable & $36 \mathrm{H}$ & -04 & 0 & Pischon T, et al. Clin Chem. 2003; 49(4): 650-652. \\
\hline & Estable & $02 \mathrm{C}$ & -30 & 0 & Shand B, et al. Chem Lab Med. 2006; 44(10): 1264-1268. \\
\hline \multirow{4}{*}{ Leptina } & Estable & $05 \mathrm{D}$ & Ambiente & 0 & Evans MJ, et al. Clin Biochem. 2001; 34(2): 107-112. \\
\hline & Estable & $05 \mathrm{D}$ & 04 & 0 & Evans MJ, et al. Clin Biochem. 2001; 34(2): 107-112. \\
\hline & Estable & $36 \mathrm{H}$ & -04 & 0 & Chu NF, et al. Clin Biochem. 1999; 32(1): 87-89. \\
\hline & Estable & $06 \mathrm{C}$ & -70 & 0 & Flower L, et al. Cytokine. 2000; 12(11): 1712-1716. \\
\hline \multirow{8}{*}{ Cistatina $\mathrm{C}$} & Estable & $25 \mathrm{~A}$ & -25 & 0 & $\begin{array}{l}\text { Gislefoss RE, et al. Clin Chem Lab Med. 2009; 47(5): 596- } \\
603 .\end{array}$ \\
\hline & Estable & $06 \mathrm{M}$ & -80 & 0 & $\begin{array}{l}\text { Erlandsen EJ, et al. Scand J Clin Lab Invest. 1999; 59(1): } \\
1-8 .\end{array}$ \\
\hline & Estable & $01 \mathrm{M}$ & -20 & 0 & $\begin{array}{l}\text { Finney H, et al. Clin Chem. 1997; 43(6 Pt 1): 1016-22. } \\
\text { Mussap M, et al. Clin Chem Lab Med. 1998; 36(11): 859- } \\
865 .\end{array}$ \\
\hline & Estable & $07 \mathrm{D}$ & 04 & 0 & Finney H, et al. Clin Chem. 1997; 43(6 Pt 1): 1016-1022. \\
\hline & Estable & $07 \mathrm{D}$ & -20 & 0 & $\begin{array}{l}\text { Erlandsen EJ, et al. Scand J Clin Lab Invest. 1999; 59(1): } \\
1-8 .\end{array}$ \\
\hline & Estable & $05 \mathrm{D}$ & 04 & 0 & $\begin{array}{l}\text { Kyhse-Andersen J, et al. Clin Chem. 1994; 40(10): 1921- } \\
1926 .\end{array}$ \\
\hline & Estable & $10 \mathrm{C}$ & -20 & 0 & Finney H, et al. Clin Chem. 1997; 43(6 Pt 1): 1016-22. \\
\hline & Estable & $07 \mathrm{C}$ & -80 & 0 & $\begin{array}{l}\text { Erlandsen EJ, et al. Scand J Clin Lab Invest. 1999; 59(1): } \\
1-8 .\end{array}$ \\
\hline \multirow{8}{*}{$25(\mathrm{OH}) \mathrm{D}$} & Estable & $40 \mathrm{~A}$ & -80 & 0 & Agborsangaya C, et al. Nutr Cancer. 2010; 62(1): 51-57. \\
\hline & Estable & $14 \mathrm{~A}$ & -20 & 0 & Bodnar LM, et al. . Clin Biochem. 2012; 45(18): 1652-1657. \\
\hline & Estable & $03 \mathrm{M}$ & -80 & 0 & $\begin{array}{l}\text { Colak A, et al. Biochem Med (Zagreb). 2013; 23(3): 321- } \\
325 .\end{array}$ \\
\hline & Estable & $14 \mathrm{D}$ & -04 & 0 & El-Khoury JM, et al. Clin Biochem. 2012; 45(9): 707-708. \\
\hline & Estable & $08 \mathrm{D}$ & Ambiente & 0 & Lewis JG, et al. .Clin Chem. 2008; 54(11): 1931-1932 \\
\hline & Estable & $07 \mathrm{D}$ & Ambiente & 0 & El-Khoury JM, et al. Clin Biochem. 2012; 45(9): 707-708. \\
\hline & Estable & $07 \mathrm{D}$ & -04 & 0 & $\begin{array}{l}\text { Bianchi S, et al. . Clin Biochem. 2012; 45(18): 1652-1657. } \\
\text { El-Khoury JM, et al. Clin Biochem. 2012; 45(9): 707-708. }\end{array}$ \\
\hline & Estable & $07 \mathrm{D}$ & -20 & 0 & $\begin{array}{l}\text { Colak A, et al. Biochem Med (Zagreb). 2013; 23(3): 321- } \\
325 .\end{array}$ \\
\hline
\end{tabular}




\begin{tabular}{|c|c|c|c|c|c|}
\hline \multirow[b]{2}{*}{ Analito } & \multirow[b]{2}{*}{ Resultado } & \multicolumn{2}{|c|}{ Característica Variable } & \multirow{2}{*}{$\begin{array}{l}\text { Unidad de } \\
\text { cambio }\end{array}$} & \multirow[b]{2}{*}{ Ref } \\
\hline & & Tiempo/Ciclos & $\begin{array}{l}\text { Temperatura } \\
\left({ }^{\circ} \mathrm{C}\right)\end{array}$ & & \\
\hline \multirow{9}{*}{$25(\mathrm{OH}) \mathrm{D}$} & Estable & $07 \mathrm{D}$ & -80 & 0 & El-Khoury JM, et al. Clin Biochem. 2012; 45(9): 707-708. \\
\hline & Estable & $03 \mathrm{D}$ & Ambiente & 0 & $\begin{array}{l}\text { Wielders JP, et al. Clin Chem. 2009; 55(8): 1584-1585. } \\
\text { Drammeh BS, et al. Clin Chem. 2008; 54(11): 1883-1891. }\end{array}$ \\
\hline & Estable & $03 \mathrm{D}$ & -04 & 0 & Bianchi S, et al. Clin Biochem. 2012; 45(18): 1652-1657. \\
\hline & Estable & $24 \mathrm{H}$ & -04 & 0 & $\begin{array}{l}\text { Bianchi S, et al. Clin Biochem. 2012; 45(18): 1652-1657. } \\
\text { Colak A, et al. Biochem Med (Zagreb). 2013; 23(3): 321- } \\
325 .\end{array}$ \\
\hline & Estable & $12 \mathrm{H}$ & Ambiente & 0 & Tanner M, et al. Ann Clin Biochem. 2008; 45(Pt 4): 375-379. \\
\hline & Estable & $11 \mathrm{C}$ & -20 & 0 & Lewis JG, et al. .Clin Chem. 2008; 54(11): 1931-1932 \\
\hline & Estable & $05 \mathrm{C}$ & -20 & 0 & Bianchi S, et al. Clin Biochem. 2012; 45(18): 1652-1657. \\
\hline & Estable & $04 \mathrm{C}$ & -20 & 0 & $\begin{array}{l}\text { Wielders JP, et al. Clin Chem. 2009; 55(8): 1584-1585. } \\
\text { Antoniucci DM, et al. Clin Chem. 2005; 51(1): 258-261. }\end{array}$ \\
\hline & Inestable & $04 \mathrm{M}$ & -20 & $\begin{array}{c}\text { Disminución } \\
15 \%\end{array}$ & Bianchi S, et al. Clin Biochem. 2012; 45(18): 1652-1657. \\
\hline \multirow{2}{*}{$25(\mathrm{OH}) \mathrm{D} 3$} & Estable & $06 \mathrm{H}$ & -04 & 0 & Mochizuki A, et al. Clin Chim Acta. 2013; 420: 114-120. \\
\hline & Estable & $05 \mathrm{C}$ & -80 & 0 & Mochizuki A, et al. Clin Chim Acta. 2013; 420: 114-120. \\
\hline
\end{tabular}

CRP(hs): Proteína C reactiva de alta sensibilidad; CRP:Proteína Creactiva; TNF-a: Factor de necrosis tumoral alfa; IL-1:Interleucina 1; IL6: Interleucina 6; CC: Cistatina C; 25(OH)D: 25 hidroxivitamina D; 25(OH) D3:1 alfa-25 dihidroxicolecalciferol; A: Año; M: Mes; D: Día; H: Hora; C: Ciclo; *: Porcentaje de variación calculado; NA: No aplica; Ref: Referencia Bibliográfica.

\section{ANALITOS CANDIDATOS PARA EL CONTROL DE CALIDAD DE MATERIAL BIOLÓGICO HUMANO ALMACENADO EN BIOBANCOS CON FINES DE INVESTIGACIÓN}

Objetivo: Identificar los biomarcadores sensibles frente a las condiciones pre-analiticas: tiempo de centrifugación, exposición a temperatura ambiente y ciclos de congelación/descongelación, a partir de los datos descritos en la literatura científica en muestras de suero y plasma humano.

Metodología: Los artículos incluidos en la tablas 2S se obtuvieron de las bases de datos PUBMED y BVS usando los siguientes términos DeCs y MeSH: Control de calidad (Quality Control), centrifugación (centrifugation), Congelación (Freezing), temperatura ambiente (Room Temperature), Variables pre-analíticas (analytical variables), Banco de muestras biológicas (biological Specimen Banks), analito (analite).

Resultados: Fueron analizados 19 artículos que cumplieron con los criterios de inclusión. Ácido úrico, GLU, BUN, GGT, CK, LDH, AST y ALT son analitos sensibles a la exposición a temperatura ambiente; ALB, CR, Lactato, GLU, $\mathrm{Ca}, \mathrm{Cl}, \mathrm{K}, \mathrm{Mg}, \mathrm{AST}, \mathrm{CK}$ y LDH presentan variaciones en su concentración por retraso en el tiempo de centrifugación y repetidos ciclos de congelación/descongelación tienen efecto sobre la concentración de los siguientes analitos: Ácido úrico, GLU, BUN, GGT, CK, LDH, AST.

Conclusión: Los hallazgos reportados en las tablas $2 \mathrm{~S}$ son importantes para el diseño de futuros estudios de investigación a partir de muestras fraccionadas y almacenadas en un biobanco. Se evidencias como posibles metabolítos para estimar la calidad dentro de los procesos del Biobanco, por su variación frente a los retrasos en el tiempo de centrifugación GLU, K, LDH y lactato y por su sensibilidad a temperatura ambiente y ciclos de descongelación GLU, GGT y LDH. 
Tabla 2S. Variación de diversos analitos frente a las variables pre-analíticas exposición a temperatura ambiente, tiempo de centrifugación y ciclos de congelación/descongelación.

\begin{tabular}{|c|c|c|c|c|c|}
\hline \multirow[b]{2}{*}{ Variable } & \multirow[b]{2}{*}{ Analito } & \multicolumn{2}{|c|}{ Característica variable } & \multirow[b]{2}{*}{$\begin{array}{l}\text { Unidad de cambio } \\
(\%)\end{array}$} & \multirow[b]{2}{*}{ Ref } \\
\hline & & Tiempo/ciclos & $\begin{array}{c}\text { Temperatura } \\
\left({ }^{\circ} \mathrm{C}\right)\end{array}$ & & \\
\hline \multirow{13}{*}{$\begin{array}{l}\text { Exposición a } \\
\text { temperatura } \\
\text { ambiente }\end{array}$} & \multirow{3}{*}{ GLU } & $02 \mathrm{H}$ & Ambiente & Disminución 7.3 & Cuhadar, et al. 2012; 22(2): 202-214. \\
\hline & & $24 \mathrm{H}$ & Ambiente & Aumenta $138.8^{*}$ & $\begin{array}{l}\text { Wilson SS, et al. Clin Chem. 1972; } \\
\text { 18(12): } 1498-503 \text {. }\end{array}$ \\
\hline & & $24 \mathrm{H}$ & Ambiente & Disminución 11.3 & $\begin{array}{l}\text { Ikeda K, et al. Biopreserv Biobank. } \\
\text { 2015; 13(2): 135-143. }\end{array}$ \\
\hline & \multirow[t]{2}{*}{ Ác. Ú. } & $02 \mathrm{H}$ & Ambiente & ND & $\begin{array}{l}\text { Taylor EC, et al. Br J Biomed Sci. } \\
2011 ; 68(3): 147-157 .\end{array}$ \\
\hline & & $02 \mathrm{H}$ & Ambiente & Aumento 2.6 & Cuhadar, et al. 2012; 22(2): 202-214. \\
\hline & \multirow[t]{2}{*}{ AST } & $24 \mathrm{H}$ & Ambiente & Disminución 39.38 & $\begin{array}{l}\text { Ikeda K, et al. Biopreserv Biobank. } \\
\text { 2015; 13(2): 135-143 }\end{array}$ \\
\hline & & $12 \mathrm{H}$ & Ambiente & Aumento 7.1 & Cuhadar, et al. 2012; 22(2): 202-214. \\
\hline & BUN & $02 \mathrm{H}$ & Ambiente & Aumento 3* & $\begin{array}{l}\text { Kang HJ, et al. Biopreserv Biobank. } \\
\text { 2013; 11(2): } 94100 .\end{array}$ \\
\hline & GGT & $01 \mathrm{H}$ & Ambiente & Aumenta $1.2 *$ & $\begin{array}{l}\text { Kang HJ, et al. Biopreserv Biobank. } \\
\text { 2013; 11(2): } 94100 .\end{array}$ \\
\hline & $\mathrm{LDH}$ & $02 \mathrm{H}$ & Ambiente & Aumenta $2.8^{*}$ & $\begin{array}{l}\text { Kang HJ, et al. Biopreserv Biobank. } \\
\text { 2013; 11(2): } 94100 .\end{array}$ \\
\hline & ALT & $24 \mathrm{H}$ & Ambiente & Disminución 24.89 & $\begin{array}{l}\text { Ikeda K, et al. Biopreserv Biobank. } \\
\text { 2015; 13(2): 135-143 }\end{array}$ \\
\hline & BT & $96 \mathrm{H}$ & Ambiente & Disminución $13 *$ & $\begin{array}{l}\text { Berg B, et al. J Clin Lab Invest. 1981; } \\
\text { 41(5): 425-430. }\end{array}$ \\
\hline & CK & $24 \mathrm{H}$ & Ambiente & Disminución 15.4 & $\begin{array}{l}\text { Ikeda K, et al. Biopreserv Biobank. } \\
2015 ; 13(2): 135-143\end{array}$ \\
\hline \multirow{13}{*}{$\begin{array}{l}\text { Tiempo de } \\
\text { centrifugación }\end{array}$} & \multirow{6}{*}{ ALB } & $24 \mathrm{H}$ & Ambiente & Aumenta 7 & $\begin{array}{l}\text { Boyanton B, et al. Clin Chem. 2002; } \\
\text { 48(12): } 2242-2247 \text {. }\end{array}$ \\
\hline & & $24 \mathrm{H}$ & Ambiente & Aumenta 1.6 & $\begin{array}{l}\text { Clark S, et al. Int J Epidemiol. 2003; } \\
\text { 32(1): } 125-130 .\end{array}$ \\
\hline & & $10 \mathrm{H}$ & Ambiente & 0 & $\begin{array}{l}\text { Henriksen LO, et al. Scand J Clin Lab } \\
\text { Invest. } 2014 \text { Oct; 74(7): 603-610. }\end{array}$ \\
\hline & & $01 \mathrm{H}$ & Ambiente & Aumenta $1.6^{*}$ & $\begin{array}{l}\text { Kang HJ, et al. Biopreserv Biobank. } \\
\text { 2013; 11(2): } 94100 .\end{array}$ \\
\hline & & $24 \mathrm{H}$ & Ambiente & Aumenta 15.2 & $\begin{array}{l}\text { Clark S, et al. Int } \mathrm{J} \text { Epidemiol. } \\
2003 ; 32(1): 125-30 .\end{array}$ \\
\hline & & $24 \mathrm{H}$ & Ambiente & Aumenta 17 & $\begin{array}{l}\text { Ono T, et al. Clin Chem. 1981; 27(1): } \\
\text { 35-38. }\end{array}$ \\
\hline & \multirow{3}{*}{$\mathrm{Ca}$} & $04 \mathrm{H}$ & 35 & Aumenta $0.8^{*}$ & $\begin{array}{l}\text { Tanner M, et al. Ann Clin Biochem. } \\
\text { 2008; 45(Pt 4): } 375-379 \text {. }\end{array}$ \\
\hline & & $08 \mathrm{H}$ & Ambiente & Aumenta 25 & $\begin{array}{l}\text { Ono T, et al. Clin Chem. 1981; 27(1): } \\
\text { 35-38. }\end{array}$ \\
\hline & & $24 \mathrm{H}$ & Ambiente & Aumenta 6 & $\begin{array}{l}\text { Boyanton B, et al. Clin Chem. 2002; } \\
\text { 48(12): } 2242-2247 \text {. }\end{array}$ \\
\hline & $\mathrm{Cl}$ & $02 \mathrm{H}$ & Ambiente & Disminución $5.5^{*}$ & $\begin{array}{l}\text { Laessig RH, et al. Am J Clin Pathol. } \\
\text { 1976; 66(3): } 598604 .\end{array}$ \\
\hline & $\mathrm{CK}$ & $24 \mathrm{H}$ & Ambiente & Disminución 0.7 & $\begin{array}{l}\text { Clark S, et al. Int J Epidemiol. 2003; } \\
\text { 32(1): } 125-130 \text {. }\end{array}$ \\
\hline & \multirow{2}{*}{$\mathrm{CR}$} & $24 \mathrm{H}$ & Ambiente & Aumento 23-40 & $\begin{array}{l}\text { Rehak N, et al. Clin Chem. 1988; } \\
\text { 34(10): 2111-2114. }\end{array}$ \\
\hline & & $04 \mathrm{H}$ & 35 & Aumenta $3.7^{*}$ & $\begin{array}{l}\text { Tanner M, et al. Ann Clin Biochem. } \\
\text { 2008; 45(Pt 4): 375-379. }\end{array}$ \\
\hline
\end{tabular}


Salud Vol.48 No.3 Julio - Septiembre de 2016

DOI: http://dx.doi.org/10.18273/revsal.v48n3-2016013

\begin{tabular}{|c|c|c|c|c|c|}
\hline \multirow[b]{2}{*}{ Variable } & \multirow[b]{2}{*}{ Analito } & \multicolumn{2}{|c|}{ Característica variable } & \multirow{2}{*}{$\begin{array}{c}\text { Unidad de cambio } \\
(\%)\end{array}$} & \multirow[b]{2}{*}{ Ref } \\
\hline & & Tiempo/ciclos & $\begin{array}{c}\text { Temperatura } \\
\left({ }^{\circ} \mathrm{C}\right) \\
\end{array}$ & & \\
\hline \multirow{20}{*}{$\begin{array}{l}\text { Tiempo de } \\
\text { centrifugación }\end{array}$} & \multirow{3}{*}{ Ác. fólico } & $24 \mathrm{H}$ & 32 & Disminución 32 & Clin Chem. 2008; 54(11): 1883-1891. \\
\hline & & $10 \mathrm{H}$ & Ambiente & Disminución 14 & $\begin{array}{l}\text { Henriksen LO, et al. Scand J Clin Lab } \\
\text { Invest. } 2014 \text { Oct; } 74(7): 603-610\end{array}$ \\
\hline & & $04 \mathrm{H}$ & Ambiente & Disminución 5.3* & $\begin{array}{l}\text { Tanner M, et al. Ann Clin Biochem. } \\
\text { 2008; 45(Pt 4): 375-379. }\end{array}$ \\
\hline & \multirow{6}{*}{ GLU } & $01 \mathrm{H}$ & Ambiente & Disminución 4.4* & $\begin{array}{l}\text { Kang HJ, et al. Biopreserv Biobank. } \\
\text { 2013; 11(2): } 94100 .\end{array}$ \\
\hline & & $02 \mathrm{H}$ & Ambiente & Aumenta 6 & $\begin{array}{l}\text { Ono T, et al. Clin Chem. 1981; 27(1): } \\
35-38 \text {. }\end{array}$ \\
\hline & & $04 \mathrm{H}$ & Ambiente & Disminución $12.3^{*}$ & $\begin{array}{l}\text { Boyanton B, et al. Clin Chem. 2002; } \\
\text { 48(12): 2242-2247. }\end{array}$ \\
\hline & & $04 \mathrm{H}$ & Ambiente & Disminución $16^{*}$ & $\begin{array}{l}\text { Tanner M, et al. Ann Clin Biochem. } \\
\text { 2008; 45(Pt 4): 375-379. }\end{array}$ \\
\hline & & $04 \mathrm{H}$ & Ambiente & Disminución 15 & $\begin{array}{l}\text { Ono T, et al. Clin Chem. 1981; 27(1): } \\
35-38 \text {. }\end{array}$ \\
\hline & & $24 \mathrm{H}$ & Ambiente & Disminución 30 & $\begin{array}{l}\text { Laessig RH, et al. Am J Clin Pathol. } \\
\text { 1976; 66(3): 598604. }\end{array}$ \\
\hline & Lactato & $04 \mathrm{H}$ & Ambiente & Aumenta $77.8^{*}$ & $\begin{array}{l}\text { Boyanton B, et al. Clin Chem. 2002; } \\
\text { 48(12): 2242-2247. }\end{array}$ \\
\hline & \multirow{3}{*}{ LDH } & $01 \mathrm{H}$ & Ambiente & Aumenta $2.8^{*}$ & $\begin{array}{l}\text { Kang HJ, et al. Biopreserv Biobank. } \\
\text { 2013; 11(2): } 94100 \text {. }\end{array}$ \\
\hline & & $04 \mathrm{H}$ & Ambiente & Aumenta $4.7^{*}$ & $\begin{array}{l}\text { Tanner M, et al. Ann Clin Biochem. } \\
\text { 2008; 45(Pt 4): 375-379. }\end{array}$ \\
\hline & & $08 \mathrm{H}$ & Ambiente & Disminución 22 & $\begin{array}{l}\text { Ono T, et al. Clin Chem. 1981; 27(1): } \\
35-38 \text {. }\end{array}$ \\
\hline & \multirow{2}{*}{$\mathrm{Mg}$} & $04 \mathrm{H}$ & Ambiente & Aumenta $2.4^{*}$ & $\begin{array}{l}\text { Tanner M, et al. Ann Clin Biochem. } \\
\text { 2008; 45(Pt 4): } 375-379 \text {. }\end{array}$ \\
\hline & & $24 \mathrm{H}$ & Ambiente & Aumenta 16 & $\begin{array}{l}\text { Boyanton B, et al. Clin Chem. 2002; } \\
\text { 48(12): 2242-2247. }\end{array}$ \\
\hline & \multirow{2}{*}{$\mathrm{K}$} & $02 \mathrm{H}$ & Ambiente & Disminución 0.6 & $\begin{array}{l}\text { Oddoze C, et al. Clin Biochem. 2012; } \\
45(6): 464-469 .\end{array}$ \\
\hline & & $04 \mathrm{H}$ & Ambiente & Disminución $4.8^{*}$ & $\begin{array}{l}\text { Tanner M, et al. Ann Clin Biochem. } \\
\text { 2008; 45(Pt 4): 375-379. }\end{array}$ \\
\hline & \multirow{2}{*}{ Urea } & $04 \mathrm{H}$ & Ambiente & Aumenta $2 *$ & $\begin{array}{l}\text { Tanner M, et al. Ann Clin Biochem. } \\
\text { 2008; 45(Pt 4): 375-379. }\end{array}$ \\
\hline & & $24 \mathrm{H}$ & Ambiente & Aumenta 6 & $\begin{array}{l}\text { Boyanton B, et al. Clin Chem. 2002; } \\
\text { 48(12): } 2242-2247 .\end{array}$ \\
\hline & $P$ & $04 \mathrm{H}$ & Ambiente & Disminuye 10 & $\begin{array}{l}\text { Ono T, et al. Clin Chem. 1981; 27(1): } \\
35-38 \text {. }\end{array}$ \\
\hline \multirow{5}{*}{$\begin{array}{l}\text { Ciclos congelación/ } \\
\text { descongelación }\end{array}$} & \multirow{2}{*}{ ALT } & $01 \mathrm{C}$ & -196 & Aumenta $2.8^{*}$ & $\begin{array}{l}\text { Kang HJ, et al. Biopreserv Biobank. } \\
\text { 2013; 11(2): } 94100 .\end{array}$ \\
\hline & & $01 \mathrm{C}$ & -20 & ND & $\begin{array}{l}\text { Taylor EC, et al. Br J Biomed Sci. } \\
2011 ; 68(3) \text { : } 147-157 .\end{array}$ \\
\hline & \multirow{2}{*}{ Ác. Ú. } & $01 \mathrm{C}$ & -20 & ND & $\begin{array}{l}\text { Taylor EC, et al. Br J Biomed Sci. } \\
2011 ; 68(3) \text { : } 147-157 .\end{array}$ \\
\hline & & $02 \mathrm{C}$ & -20 & Aumenta 2.2 & $\begin{array}{l}\text { Cuhadar S, et al. Biochem Med } \\
\text { (Zagreb). 2013; 23(1): 70-77. }\end{array}$ \\
\hline & GLU & $01 \mathrm{C}$ & -196 & Aumenta $2.7^{*}$ & $\begin{array}{l}\text { Kang HJ, et al. Biopreserv Biobank. } \\
\text { 2013; 11(2): } 94100 .\end{array}$ \\
\hline
\end{tabular}


Control de calidad del material biológico humano recolectado con fines de investigación

\begin{tabular}{|c|c|c|c|c|c|}
\hline \multirow[b]{2}{*}{ Variable } & \multirow[b]{2}{*}{ Analito } & \multicolumn{2}{|c|}{ Característica variable } & \multirow{2}{*}{$\begin{array}{l}\text { Unidad de cambio } \\
\text { (\%) }\end{array}$} & \multirow[b]{2}{*}{ Ref } \\
\hline & & Tiempo/ciclos & $\begin{array}{l}\text { Temperatura } \\
\left({ }^{\circ} \mathrm{C}\right)\end{array}$ & & \\
\hline \multirow{6}{*}{$\begin{array}{l}\text { Ciclos congelación/ } \\
\text { descongelación }\end{array}$} & GLU & $01 \mathrm{C}$ & -70 & Aumenta 11.8 & $\begin{array}{l}\text { Flood A, et al. . Division of Cancer } \\
\text { Epidemiology and Genetics. } 2002 .\end{array}$ \\
\hline & & $03 \mathrm{C}$ & -70 & Disminución $5.9^{*}$ & $\begin{array}{l}\text { DiMagno EP, et al. Mayo Clin Proc. } \\
\text { 1989; 64(10): 1226-1234. }\end{array}$ \\
\hline & LDH & $01 \mathrm{C}$ & -196 & Aumenta $3.3 *$ & $\begin{array}{l}\text { Kang HJ, et al. Biopreserv Biobank. } \\
\text { 2013; 11(2): } 94100 .\end{array}$ \\
\hline & BUN & $01 \mathrm{C}$ & -196 & Aumenta $10.9^{*}$ & $\begin{array}{l}\text { Kang HJ, et al. Biopreserv Biobank. } \\
\text { 2013; 11(2): } 94100 .\end{array}$ \\
\hline & $\mathrm{CK}$ & $02 \mathrm{C}$ & -70 & Disminución $6.8^{*}$ & $\begin{array}{l}\text { DiMagno EP, et al. Mayo Clin Proc. } \\
\text { 1989; 64(10): 1226-1234. }\end{array}$ \\
\hline & GGT & $01 \mathrm{C}$ & -196 & Aumenta $3.6^{*}$ & $\begin{array}{l}\text { Kang HJ, et al. Biopreserv Biobank. } \\
\text { 2013; 11(2): } 94100 .\end{array}$ \\
\hline
\end{tabular}

Ác.Ú.: Ácido úrico; BUN: Nitrógeno ureico; GLU: Glucosa; BT: Bilirrubina total; CR: Creatinina; ALB: Albumina; Ác. Fólico: Ácido fólico; GGT: Gamma glutamil transferasa; LDH: Lactato deshidrogenasa; ALT: Alanino aminotransferasa; AST: Aspartato aminotransferasa; CK: Creatina quinasa; Cl: Cloro; Mg: Magnesio; Ca: Calcio; K: Potasio; P: Fósforo; *: Porcentaje de variación calculado; ND: No registra dato; Ref: Referencia Bibliográfica. 